\title{
An introduction to embodied cognition
}

\author{
Mansoor Fahim, Atefeh Rezanejad* \\ Department of Foreign Languages and Literature, Allameh Tabataba'i University, Tehran, Iran \\ Email address: \\ dr.manfahim@yahoo.com (M. Fahim),rezanejad_a85@yahoo.com (A. Rezanejad)
}

To cite this article:

Mansoor Fahim, Atefeh Rezanejad. An Introduction to Embodied Cognition. International Journal of Language and Linguistics.

Vol. 2, No. 4, 2014, pp. 283-289. doi: 10.11648/j.ij1l.20140204.16

\begin{abstract}
This paper aimed at providing an overview on the post-cognitivist approach of embodiment theory. In the first section, a summary of the main tenets of the traditional cognitive theory are provided. Following the pros and cons of traditional cognitive theory, section two introduces the new trend in the field of cognitive science, i.e. the embodied cognitive approach. Then the main features and claims of embodiment theory are presented in section three. In sections four and five the confusions over the issue of embodiment and different types of embodiment are presented correspondingly, following a final conclusion section.
\end{abstract}

Keywords: Cognitive Science, Embodiment, Review

\section{Traditional Cognitive Theory}

The emergence of cognitive linguistics goes back to no longer than two decades ago. Cognitive linguistics developed in 1970 s out of the academic work of some scholars who did not believe in the linguistic explanations of patterns of language through adherence to mere structural patterns and properties of certain languages. On the contrary, they strongly had faith in the relationships existing between language and mind, a fact which has been neglected to the time. That is to say, the central focus of study shifted to meaning.

Cognitive linguistics appeared as a powerful tool and approach to study the language, mind, cognition, conceptual system, and the construction of meaning. Within the realm of language, it was concerned with some rudimentary conceptual and abstract entities such as sense of motion and locus, place and time, sights and events, and also processes of cause and effect (Talmy, 2000).

Regarding the notion of cognitive linguistics, in Encyclopedia of Cognitive Science Cognitive Linguistics Gilles Fauconnier (2006: 1) writes:

Cognitive linguistics recognizes that the study of language is the study of language use and that when we engage in any language activity, we draw unconsciously on vast cognitive and cultural resources, call up models and frames, set up multiple connections, coordinate large arrays of information, and engage in creative mappings, transfers, and elaborations. Language does not "represent" meaning; it prompts for the construction of meaning in particular contexts with particular cultural models and cognitive resources. Very sparse grammar guides us along the same rich mental paths, by prompting us to perform complex cognitive operations. Thus, a large part of cognitive linguistics centers on the creative on-line construction of meaning as discourse unfolds in context. The dividing line between semantics and pragmatics dissolves and truth-conditional compositionality disappears ... Cognitive linguistics goes beyond the visible structure of language and investigates the considerably more complex backstage operations of cognition that create grammar, conceptualization, discourse, and thought itself. The theoretical insights of cognitive linguistics are based on extensive empirical observation in multiple contexts, and on experimental work in psychology and neuroscience.

Cognitive science is considered to be dealing with the scientific study of the mind and its operations from an interdisciplinary perspective. It is mainly concerned with probing the internal features of cognition, its responsibilities and how it works. The scholars in the field of cognitive science have dealt with a wide range of topics and issues such as intelligence and behavior, and representation, processing and transformation of information through language, memory, perception, and reasoning within neurons in humans, animals, and even machines such as computer. What needs to be mentioned is that the field of cognitive science is so wide and includes 
numerous different disciplines such as anthropology, psychology, artificial intelligence, philosophy, neuroscience, and also linguistics. The deep-seated concept of cognitive science is said to be that thinking should be understood in terms of representational structures of the mind along with some computational procedures which will operate on them (Zalta, 2004).

Nevertheless, along with all encouraging features of the approach, traditional cognitivism is believed to contain some drawbacks and deficiencies. For instance, the leading arguments is that in traditional cognitivism cognition is entirely concerned with thoughts, thinking, and beliefs and not much is devoted to sensing and acting (Barsalou, Breazeal, \& Smith, 2007). As some scholars (Bickhard, 2008; Pylyshyn, 1980) argue, the best realization of cognition was summarized in symbolic processing. But the point is that human cognitive system has the ability to represent, symbolize, and embody things (concrete \& abstract) in the world and the traditional version of cognitivism was not successful in explaining how this ability develops in the cognitive system and where these abstract representations are located in brain (Barsalou, 2008a, 2008b; Gallese, \& Lakoff, 2005). Moreover, another problem, which is called the symbol grounding problem, remains to be the inability of traditional cognitivism in clarifying how do symbols get their meaning attributed to them (Harnad, 1990, cited in Ionescu \& Vasc, 2013: 276). "Considering the cognitive system a purely symbolic one makes it difficult to pinpoint its specific mechanisms and their precise locations in the brain, and to understand its connection to the real world" (Ionescu \& Vasc, 2013: 276).

Reviewing the literature indicates that new trends are welcomed in cognitive science around the world in order to propose new insights and compensate for the above mentioned drawbacks in the field (Clark, 2011; Crollen, Dormal, Seron, Lepore, \& Collignon, 2013; Maouene, \& Ionescu, 2011; Riegler, 2002; Schubert, \& Semin, 2009; Wilson, 2002). Numerous studies (e.g. on conceptual knowledge: Boncoddo, Dixon, \& Kelley, 2010; Borghi, Glenberg, \& Paschak, 2004; Vankov, \& Kokinov, 2013, learning mathematics: Goldin-Meadow, \& Singer, 2003; Goldin-Meadow, Wagner Cook, \& Mitchell, 2009; Wagner Cook, 2011, language learning: Maouene, Sethuraman, Laakso, \& Maouene, 2011, language comprehension: Glenberg, Sato, Cattaneo, Riggio, Palumbo, \& Buccino, 2008) by different scholars in various fields of studies point out that unlike previous findings and propositions of the cognitive science, the human cognitive system is to a great extent relies on the sensory-motor processes and thinking and though cannot be divorced from sensing and action.

\section{The Embodied Cognitive Approach}

As Gomila, \& Calvo (2008) argue, cognition cannot be separated from education and the two are totally interrelated. The main goal of education is enabling people to freely solve the problems they face and this surely stresses the necessity of figuring out what cognition itself is. The point is that the notion of cognition has undergone through various different definitions and has experienced some transformations in the way it is viewed. Unlike past, cognition is not thought to be amodal and dissimilar to perceptions and acting (Smith, \& Sheya, 2010). But it is now believed that cognition, body, and context are three interrelated concepts which are in constant interactions with each other. (Barsalou, 2008a; Clark, 2011; Ionescu, 2011; Laakso, 2011; Schubert, \& Semin, 2009; Stapleton, 2013). No need to mention that by body we mean sensory-motor systems, bodily actions, feelings, and also emotions. The post-cognitivist approach which in fact supports these claims is called the embodied cognition approach. According to this approach, body is a key element in shaping our cognition. To put it another way, "cognition is at any time influenced by the morphology of our bodies and by its sensory-motor systems" (Glenberg, 2008, cited in Ionescu \& Vasc, 2013: 276).

Since the middle of 1980 s, the field of cognitive science and artificial intelligence has increasingly welcomed discussions over the concept of embodiment (Clark 1997; Lakoff \& Johnson, 1999; Haselager 2004). The concept has experienced many different terms such as embodied AI (e.g. Franklin, 1997), embodied cognition (e.g. Clark, 1997), embodied cognitive science (e.g. Clark, 1999; Pfeifer \& Scheier, 1999), embodied mind (e.g. Lakoff \& Johnson, 1999; Varela, Thompson, \& Rosch, 1991), embodied intelligence (e.g. Brooks, 1991), and embodied action (e.g. Varela, Thompson, \& Rosch, 1991).

The core inspiration underlying the theory of embodied cognition is that interactions of the body with the environment can hold a great impact on the type and shaping of the cognitive processes (Chiel \& Beer 1997, cited in Kerkhofs \& Haselager, 2006). "The body is more than a mere transducer of information between the organism and the environment: It actively shapes the form cognitive tasks can take and also presents possibilities for solving them. If this position is right, it should be possible to find traces of sensorimotor interactions with environment, of aspects of perception and action, in the way organisms understand (and respond to) meaning" (Kerkhofs \& Haselager, 2006: 2). Anderson (2005: 2) believes that embodied cognition "treats cognition as a set of tools evolved by organisms for coping with their environments".

In other words, bodily actions, movements, and gestures are intricately interrelated with representations of meaning. "Meaning depends on an individual's history of bodily interactions with the world. People recreate those experiences in response to linguistic input, and use them to produce meaningful linguistic output. From this perspective, perceptual and motor processes are not peripheral to but form the core of mental content" (Kerkhofs \& Haselager, 2006: 2). In the same lines, Glenberg \& Robertson (2000: 383) argue "when affordances, experiences, and goals are successfully meshed, they form a coherent, doable, and 
envisionable set of actions: the individual's meaningful construal of the situation."

Pulvermüller (2013: 87) refers to some recent scholars' views regarding the topic (Barsalou, 2008a; de Vega, Graesser, \& Glenberg, 2008; Fischer \& Zwaan, 2008; Kiefer \& Pulvermüller, 2012; Meteyard, Cuadrado, Bahrami, \& Vigliocco, 2012) and states that "Theories are sometimes called embodied, because they ground cognitive processes in bodily action and perception". He further continues that the theory "implies that action and perception mechanisms play a role in the semantics of at least some words, symbols and constructions, but it does not preclude other (nonmotor and nonsensory) mechanisms to contribute to semantics". However, the point is that the theory has welcomed many different definitions and features and there is not yet any consensus among different scientists regarding the features and definitions. For instance, for Mahon \& Caramazza (2008: 59) embodiment means "that conceptual content is reductively construed by information that is represented within the sensory and motor systems".

Besides different ways of addressing the topic, different scholars have also introduced different types of embodiment such as situated embodiment (Zlatev, 1997), natural embodiment (Ziemke, 1999), mechanistic embodiment (Sharkey \& Ziemke, 2001), phenomenal embodiment (Sharkey \& Ziemke, 2001), naturalistic embodiment (Zlatev, 2001).

The concept of embodied cognition (EC) typically refers to a wide variety of disciplines within cognitive science; for instance: artificial intelligence, robotics, psychology, cognitive neuroscience, philosophy, linguistics, cognitive anthropology. "Within the EC approach, some authors emphasize the importance of action for cognition and the role played by bodily states, others high-light more generally the role of grounding for cognition and equate embodied cognition with situated cognition" (Borghi \& Cimatti, 2009: 763). We will end this section with a concluding comment from Kerkhofs \& Haselager (2006, p. 7) "The idea of embodiment in cognitive science is quite straightforward - it is the notion that aspects of cognition cannot be understood without referring to aspects of the systems they are embedded in - in the biology of the organism, including its brain and the rest of its body, and in its physical and social context.

\section{Six Main Claims of Embodied Cognition}

Wilson (2002) summarized the six basic features of embodied cognition as follows:

\subsection{Cognition is Situated}

This feature seems to be the foundation of embodiment theories. Most of the scholars on the field have paid some attention to this feature (e.g., Chiel \& Beer, 1997; Clark,
1997; Pfeifer \& Scheier, 1999; Steels \& Brooks, 1995). As the name suggests, it denotes cognition which is situation bound. As Wilson (2002: 626) puts it, "situated cognition is cognition that takes place in the context of task-relevant inputs and outputs. That is, while a cognitive process is being carried out, perceptual information continues to come in that affects processing, and motor activity is executed that affects the environment in task-relevant ways". Some examples of such cognitive activities are situated are also provided such as "driving, holding a conversation, and moving around a room while trying to imagine where the furniture should go" (Wilson, 2002: 626).

\subsection{Cognition is Time Pressured}

"A belief in the importance of time pressure as a shaping force in cognitive architecture underlies much of the situated cognition literature" (Wilson, 2002: 627). For instance in the field of robotics, scientists could make robots which are able to perform complex tasks according the context and the situation they are in. That is to say they need to provide some feedbacks to the environment they are interacting with. Now why time pressure matters this much? Wilson (2002) argues that the reason lies in the provision of a representational bottle-neck. "When situations demand fast and continuously evolving responses, there may simply not be time to build up a full-blown mental model of the environment, from which to derive a plan of action. Instead, it is argued, being a situated cognizer requires the use of cheap and efficient tricks for generating situation-appropriate action on the fly" (Wilson, 2006: 628).

\subsection{We Off-Load Cognitive Work onto the Environment}

Whereas we frequently undergo cognitive processes in an off-line fashion, still many other cognitive actions are processes on-line. It seems that we human beings are capable of coming over our cognitive limitations and manage mental activities when confronting them. This can be achieved in a number of ways. Human beings usually rely on their previous knowledge and schemata in order to solve problems. That is to say prior learning experiences come to help. In some other cases, especially when facing new stimuli, people may use the environment to overcome cognitive load by leaving information in the environment to be accessed later (Wilson, 2002).

Some scholars such as Kirsh and Maglio (1994) have tried to investigate the issue through some experiments. They did the experiment on the specific game of Tetris. The results of their study indicated that the players didn't in fact compute a solution for the problem in their minds and then operate it. Rather, results showed that the game was played in an on-line fashion.

\subsection{The Environment is Part of the Cognitive System}

Till here we know that according to embodied cognition body and environment play an important role in cognitive 
activities. The fourth claim has gone still further and states that "cognition is not an activity of the mind alone, but is instead distributed across the entire interacting situation, including mind, body, and environment (Wilson, 2002: 630).

The main idea of this claim is summarized by Wilson (2002: 630) as "The forces that drive cognitive activity do not reside solely inside the head of the individual, but instead are distributed across the individual and the situation as they interact. Therefore, to understand cognition we must study the situation and the situated cognizer together as a single, unified system.".

\subsection{Cognition is for Action}

"The function of the mind is to guide action, and cognitive mechanisms such as perception and memory must be understood in terms of their ultimate contribution to situation-appropriate behavior." (Wilson, 2002: 626).

\subsection{Off-Line Cognition is Body Based}

"Even when decoupled from the environment, the activity of the mind is grounded in mechanisms that evolved for interaction with the environment - that is, mechanisms of sensory processing and motor control." (Wilson, 2002: 626).

In the same lines, Michael L. Anderson (2005: 3) enumerates the following six characteristics for the theory:

(1) Cognition, like every other adaptation, has an evolutionary history that can be useful in understanding its function;

(2) Perhaps more importantly, cognition evolved because it was adaptive - that is, it enhanced survival and reproductive success primarily by allowing more effective coping with the environment;

(3) Cognition evolved in specific environments, and its solutions to survival challenges can be expected to take advantage of the concrete structure or enduring features of those environments;

(4) Cognition evolved in organisms with specific physical attributes, bodies of a certain type with given structural features, and can therefore be expected to be shaped by and to take advantage of these features for cognitive ends. ... the primary physical organ system supporting cognition, the central nervous system, is also, and of course not coincidentally, the organ system responsible for perception and the coordination and control of action, making quite natural the motto (to paraphrase Clark, 1998) that the mind is first and foremost the control system for the body. Indeed, cognition is to be seen precisely as a complex adaptation of the body's control system to aid survival and reproductive success. Moreover, these physical features were not immutable, and we know that there has been co-evolution of physical and cognitive attributes, as for instance between the primate, and human, hand and brain (Wilson, 1998).
Thus, what this means is not just that physical attributes (bigger brains, better neurons, etc.) changed over time, and were preserved if they better served cognition, but that cognition evolved in light of, and in the context of, a given physical system, and therefore that certain cognitive attributes would have been preserved just in case they (better) served that particular organism, whether or not that feature or solution would be optimal by other measures or appropriate for other organisms;

(5) Cognition evolved in organisms with pre-existing sets of behavioral possibilities, instincts, habits, needs, purposes, and the like. The evolutionary process would have taken advantage of these possibilities, preserving some and altering others, and incorporating them into its solutions - for instance, taking advantage of certain pre-existing dispositions to manipulate the environment or one's relation to it, which dispositions may have evolved for reasons unrelated to cognitive enhancement.

(6) As with the other bodily organs, (co-)evolved to solve specific problems of bodily function in light of already evolved (and evolving) organs, we shouldn't be surprised to find the organ(s) of cognition to:

a. Be composed of basic functional units with limited variation (e.g. neurons);

b. Involve repeated and redundant functional structures at slightly higher levels of organization (e.g. XOR gates);

c. Evince high degrees of specialization at the highest levels of organization (e.g. specialized modules). This means, among other things, that there need be no universal cognitive solutions;

d. Rely for their function on the operation of other functional units, organs and organ systems, (e.g. interactions between cognition, action, and perception); and

e. Be coordinated without requiring extensive central control (which does not rule out central control in specific cases)." (p. 3).

\section{Confusions about Embodiment Theory}

Pulvermüller (2013) refers to some misrepresentations regarding the topic of embodied cognition. He believes that in many cases the leading features and characteristics of the theory have been misrepresented and needs some clarification. A complete list of his arguments is presented below:

(1) Embodied theories do not construe semantics reductively in terms of motor and sensory information.

(2) Action perception representations do not merely have a non-constitutive "dressing" or "coloring" role in conceptual-semantic processing; this 
minimally-embodied view is difficult to reconcile with causal effects of action systems on semantically-specific processes.

(3) Functional interaction between action, perception and multimodal systems implies that if one of these systems processes meaning, the others do so too.

(4) Meaning processing without reference is incomplete; symbol grounding is necessary for semantics.

(5) Abstract words, like concrete ones, need to be explained and grounded in the context of concrete actions and perceptions; otherwise semantic learning is difficult to achieve. In addition,

(6) common double dissociations between perception and action are consistent with embodied distributed circuits, which

(7) can act as integration devices for multimodal semantic information. Therefore, previous criticisms of embodied approaches cannot be maintained and alternative minimally-embodied proposals are insufficient (p. 92).

\section{Different Types of Embodiment}

Regarding the different types of embodiment, Michael L. Anderson (2005) mentions some four different kinds. They include: structured coupling embodiment, historical embodiment, Physical, organismoid, and organismic embodiment, and social embodiment. In this section we would present a brief explanation for each type. The explanations are directly taken from the entry of the encyclopedia, entitled as: How to study the mind: An introduction to embodied cognition.

a. Embodiment as structural coupling

“... (according to) Quick et al. (1999), "A system X is embodied in an environment $\mathrm{E}$ if perturbatory channels exist between the two." That is, if there is the bi-lateral possibility that each system can affect (perturb, change the states of) the other, they are structurally coupled. As Ziemke notes, as a restrictive definition of embodiment, meant to distinguish systems that are embodied from those that are not, this leaves much to be desired." (Anderson, 2005:13).

b. Historical embodiment

"This aspect of embodiment emphasizes that the character of an agent's cognitive processes owes a great deal to continuous and repeated interaction with the environment, not just in the evolutionary history of the species ... but also in the lifetime of the individual agent. The agent adapts to its environment over both evolutionary and individual time ... and its cognitive processes thereby reflect the fact and character of this interaction. Here again, the task for the EC researcher is to identify the specific ways in which such interactions matter to, and are reflected in, the character of the agent's cognition." (Anderson,
2005: 13).

c. Physical, organismoid, and organismic embodiment "These aspects of embodiment express three increasingly restrictive levels of physical instantiation: unrestricted physical instantiation; physical instantiation in an organism-like body (possessing some similar degree of autonomy and sensorimotor capacity as a living organism); and physical instantiation in an actual living body. Although each of these appear very different from the standpoint of restrictively defining the minimal amount or type of embodiment required to support EC, they are for our purposes the same, in that their utility is to draw attention to the ways in which the specific physical characteristics of a cognitive system affect the nature and character of its cognitive processes." (Anderson, 2005: 13).

d. Social embodiment

"This aspect of embodiment emphasizes that at least some organisms are coupled not just with a physical environment, but also with a social one, and that therefore there exist various perturbatory channels between the organism and the social world that also matter to the character of its cognitive processes." (Anderson, 2005: 13).

\section{Conclusion and Implications}

In this paper we tried to provide an overview over the concept of embodiment which is one of the most important post-cognitivist approaches. Contemplating over the issue and raising awareness on the concept can increase one's understandings on the topic. In addition, as Ionescu \& Vasc (2013: 278) argue, this will lead to some theoretical and practical implications in the field of education: "at a theoretical level, embodied cognition could bring us closer to a complete understanding of what cognition is; at a practical level, embodiment may lead to more individuals who are well educated and can use the knowledge they learned in school in real life settings". Researching embodiment will in addition open new doors of research and investigation in the field of cognitive science. According to Anderson (2003: 126) "Against the cognitivist claim that cognition is the rule-based manipulation of abstract representations, EC maintains that there is much more to cognition than mental representation. Cognition exploits repeated interaction with the environment, not only using the world as its own best model, but creating structures which advance and simplify cognitive tasks".

\section{References}

[1] Anderson, M. L. (2003). Embodied cognition: A field guide. Artificial intelligence, 149(1), 91-130.

[2] Anderson, M. (2005). How to study the mind: An introduction to embodied cognition. Embodied Cognition and Perceptual Learning in Adaptive Development. 
[3] Barsalou, L. W. (2008a). Grounded Cognition. Annual Review of Psychology, 59, 617-645.

[4] Barsalou, L.W. (2008b). Cognitive and Neural Contributions to Understanding the Conceptual System. Current Directions in Psychological Science, 17, 91-95.

[5] Barsalou, L. W., Breazeal, C., \& Smith, L. B. (2007). Cognition as coordinated non-cognition. Cognitive Processing , 8, 79-91.

[6] Bick Hard, M. H. (2008). Is Embodiment Necessary? In Calvo P. \& Gomila A. (Eds.), Handbook of Cognitive Science: An Embodied Approach, San Diego, Elsevier.

[7] Boncoddo, R., Dixon, J. A., \& Kelley, E. (2010). The emergence of a novel representation from action: evidence from preschoolers. Developmental Science, 13, 370-377.

[8] Borghi, A. M., \& Cimatti, F. (2012). Words are not just words: the social acquisition of abstract words. Rivista Italiana di Filosofia del Linguaggio, 5, 22-37.

[9] Borghi, A.M., Glenberg, A.M., \& Paschak, M.P. (2004). Putting Words in Perspective. Memory \& Cognition, 32, 863-873.

[10] Brooks, R. (1991). Intelligence Without Reason. Proceedings of the Twelfth Intl. Joint Conf. on Artificial Intelligence. San Mateo, CA: Morgan Kaufmann.

[11] Chiel, H., \& Beer, R. (1997). The brain has a body: Adaptive behavior emerges from interactions of nervous system, body, and environment. Trends in Neurosciences, 20, 553-557.

[12] Clark, A. (1997). Being There. Cambridge: MIT Press.

[13] Clark, A. (1998). Embodied, situated, and distributed cognition. In W. Bechtel and G. Graham (eds.), A Companion to Cognitive Science. Malden, MA: Blackwell Publishers.

[14] Clark, A. (1999). An embodied cognitive science? Trends in Cognitive Science, 9, 345-351.

[15] Clark, A. (2011). Supersizing the Mind: Embodiment, Action, and Cognitive Extension. Oxford University Press, New York.

[16] Crollen, V., Dormal, G., Seron, X., Lepore, F., \& Collignon, O. (2013). Embodied numbers: The role of vision in the development of number-space interactions. Cortex, 49, 276-283.

[17] De Vega, M., Graesser, A., \& Glenberg, A. M. (2008). Framing the debate. In M. de Vega, A. Graesser, \& A. M. Glenberg (Eds.), Symbols, embodiment, and meaning (pp. 85-116). Oxford: Oxford University Press.

[18] Fauconnier, G. (2006). Cognitive linguistics. Encyclopedia of cognitive science.

[19] Fischer, M. H., \& Zwaan, R. A. (2008). Embodied language: A review of the role of the motor system in language comprehension. The Quarterly Journal of Experimental Psychology (Colchester), 61(6), 825-850.

[20] Franklin, S. (1997) Autonomous agents as embodied AI. Cybernetics and Systems, 25(8), 499-520.

[21] Galesse, V., \& Lakoff, G. (2005). The Brain's Concepts:
The Role of the Sensory-Motor System in Conceptual Knowledge. Cognitive Neuropsychology, 22, 455-479.

[22] Glenberg, A.M. (2008a). Embodiment as a Unifying Perspective for Psychology, Advanced Review, John Wiley \& Sons Ltd., 1, 586-596.

[23] Glenberg, A.M. \& Robertson, D.A. (2000). Symbol grounding and meaning: A comparison of high-dimensional and embodied theories of meaning. Journal of memory and language, 43, 379-401.

[24] Glenberg, A.M., Sato, M., Cattaneo, L., Riggio, L., Palumbo, D., \& Buccino, G. (2008). Processing Abstract Language Modulates Motor System Activity. The Quaterly Journal of Experimental Psychology, 61, 905-919.

[25] Goldin-Meadow, S., \& Singer, M. A. (2003). From Children's Hands to Adults' Ears: Gesture's Role in the Learning Process. Developmental Psychology, 39, 509-520.

[26] Goldin-Meadow, S., Cook, S. W., \& Mitchell, Z. A (2009). Gesturing gives children new ideas about math. Psychological Science, 20(3), 267-272.

[27] Gomila, T. \& Calvo, P. (2008). Directions for an Embodied Cognitive Science: Toward an Integrated Approach. In Calvo P. \& Gomila A. (Eds.), Handbook of Cognitive Science: An Embodied Approach, San Diego, Elsevier.

[28] Harnad, S. (1990). The Symbol Grounding Problem. Physica, 42, 335-346.

[29] Haselager, W. F. G. (2004). O mal estar do representacionismo: sete dores de cabeça da Ciência Cognitiva (The indisposition of representationalism: Seven headaches of cognitive science). In Encontros com as Ciências Cognitivas. A. Ferreira, M. E. Q. Gonzalez and J. G. Coelho (Eds.). São Paulo, Coleção Estudos Cognitivos, 4, 105-120.

[30] Ionescu, T. (2011). Abordarea "embodied cognition" úi studiul dezvolt ă rii cognitive. Revista de Psihologie, 57, 326- 339.

[31] Ionescu, T., \& Vasc, D. (2013). Embodied cognition: challenges for psychology and education. Procedia - Social and Behavioral Sciences, 128, 275-280.

[32] Kerkhof s, R. \& Haselager, W.F.G. (2006). The embodiment of meaning. Manuscrito, 29(2), 753-764.

[33] Kiefer, M., \& Pulvermüller, F. (2012). Conceptual representations in mind and brain: Theoretical developments, current evidence and future directions. Cortex, 48(7), 805-825. http://dx.doi.org/10.1016/j.cortex.2011.04.006.

[34] Laakso, A. (2011). Embodiment and development in cognitive science. Cognition, Brain, Behavior: An Interdisciplinary Journal (Special Issue: Embodiment and Development), 15, 409- 425.

[35] Lakoff, G. \& Johnson, M. (1999). Philosophy in the flesh: The embodied mind and its challenge to western thought. New York: Basic Books.

[36] Mahon, B. Z., \& Caramazza, A. (2008). A critical look at the embodied cognition hypothesis and a new proposal for grounding conceptual content. Journal of Physiology Paris, 102(1-3), 59-70. 
[37] Maouene, J., \& Ionescu, T. (Eds.) (2011). Embodiment and Development. Special Issue of Cognition, Brain, Behavior. An interdisciplinary Journal, 15(4), 124-138.

[38] Maouene, J., Sethuraman, N., Laakso, A., \& Maouene, M. (2011). The Body Region Correlates of Concret and Abstract Verbs in Early Child Language. Cognition, Brain, Behavior: An Interdisciplinary Journal (Special Issue: Embodiment and Development), 15, 449- 481.

[39] Meteyard, L., Cuadrado, S. R., Bahrami, B., \& Vigliocco, G. (2012). Coming of age: A review of embodiment and the neuroscience of semantics. Cortex, 48 (7), 788-804. http://dx.doi.org/10.1016/j.cortex.2010.11.002.

[40] Pfeifer, R. \& Scheier, C. (1999). Understanding Intelligence. Cambridge, MA: MIT Press.

[41] Pulvermueller, F. (2013). Semantic embodiment, disembodiment or misembodiment? In search of meaning in modules and neuron circuits. Brain and language, 127(1), 86-103.

[42] Pylyshyn, Z. W. (1980). Computation and cognition: issues in the foundations of cognitive science. The Behavioral and Brain Sciences, 3, 111-169.

[43] Vankov, I., \& Kokinov, B. (2013). The role of the motor system in conceptual processing: Effects of object affordances beyond response interference. Acta Psychologica, 143, 52-57.

[44] Varela, F.; Thompson, E. \& Rosch, E. (1991). The Embodied Mind. Cambridge, MA: MIT Press.

[45] Riegler, A. (2002). When is a cognitive system embodied? Cognitive Systems Research, 3, 339-348.

[46] Schubert, T.W., \& Semin, G.R. (2009). Embodiment as a Unifying Perspective for Psychology. European Journal of Social Psychology, 39, 1135-1141.
[47] Sharkey, N. \& Ziemke, T. (2001). Mechanistic vs. phenomenal embodiment - Can robot embodiment lead to strong AI? Cogn. Systems Res., 2(4), 251-262.

[48] Smith, L. B., \& Sheya, A. (2010). Is cognition enough to explain cognitive development? Topics in Cognitive Science, 4, 1-11.

[49] Stapleton, M. (2013). Steps to a "Properly Embodied" cognitive science. Cognitive Systems Research, 22(2), 1-11.

[50] Steels, L., \& Brooks, R. (1995). The artificial life route to artificial intelligence: Building embodied, situated agents. Hillsdale, NJ: Erl-baum

[51] Talmy, L. (2000). Toward a Cognitive Semantics. Cambridge, Mass.: MIT Press.

[52] Wagner Cook, S. (2011). Abstract Thinking in Space and Time: Using Gesture to Learn Math. Cognition, Brain, Behavior: An Interdisciplinary Journal (Special Issue: Embodiment and Development), 15, 553- 570.

[53] Wilson, F. (1998). The Hand: How its use shapes the brain, language and human culture. New York: Pantheon.

[54] Wilson, M. (2002). Six views of embodied cognition. Psychonomic Bulletin \& Review, 9(4), 625-636.

[55] Zalta, E. N. (2004). The Stanford Encyclopedia of Philosophy.

[56] Ziemke, T. (1999). Rethinking Grounding. In A. Riegler et al. (Eds.), Understanding Representation in the Cognitive Science. Plenum Press: New York.

[57] Zlatev, J. (1997). Situated embodiment: Studies in the emergence of spatial meaning. Stockholm: Gotab.

[58] Zlatev, J. (2001). The epigenesis of meaning in human beings, and possibly in robots. Minds and Machines, 11, 155-195. 